\title{
Henry Dunn: An Appreciation
}

Henry Dunn was born into a medical family in Leipzig, Germany. His father was a dermatologist and his older brother grew up to be an obstetrician-gynecologist. After primary education in Germany, he completed his schooling in England and then studied medicine at Trinity College, Cambridge and the London Hospital. This was of course during wartime and after he graduated in 1942 and had been an intern (or "resident") for a short time he joined the Royal Army Medical Corps as a Lieutenant. He saw service mainly in India and was promoted to Major before his discharge. He then embarked upon his future career, that of paediatrics, and trained at the Hospital for Sick Children, Great Ormand Street, London and the Babies Hospital, New York. Some of his mentors included Philip Evans, Wilfred Sheldon and the great Dorothy Andersen. He came to British Columbia as chief resident, and in 1954 became F.R.C.P.(C). After a short spell in paediatric practice in New Westminster, he was attracted by Dr. Jack McCreary to the academic department of paediatrics and studied pediatric neurology in Boston under such eminent neurologists as Raymond Adams, Randolph Byers and Charles Barlow.

When he returned to Canada he was the first pediatric neurologist to have reached that position from the discipline of paediatrics (Drs. Stobo Prichard and Preston Robb were the only other paediatric neurologists at that time). For that reason he likes to describe himself as a neuropediatrician and he was fond of quoting Dr. Sven Brandt, who maintained that paediatric neurology had a father (neurology) and a mother (paediatrics). He held to this precept throughout his professional life. He still has a rather moth-eaten monkey puppet in his case alongside his ophthalmoscope.
He proceeded to set up a pediatric neurology service in the west of Canada which, it immediately became evident, could not be run by himself alone despite the enormously long hours which he has always worked. Over the years he was joined by others and the training program which he initiated is recognized as one of the best in North America. Despite this very busy clinical load, his output of original work has, as is well known, not only been plentiful; it has also been catholic and innovative. Fragile X mental retardation is one topic which owes its description largely to Henry. He also made significant contributions to peripheral nerve disease in children, and wrote a classical monograph on the Prader-Willi syndrome. His team of researchers into the long-term fate of the low birth weight infant made significant contributions to this topic.

Henry's capacity for work has daunted all those who have worked with him. Work days did not end till 11:30 or midnight and the detailed observations he made on his clinical cases are models of clinical accuracy. Along with this, he demonstrates a degree of solicitude for his patients which is a model for his trainees. His knowledge is encyclopedic, and remarkably au fait with advances in medical knowledge, as we know from attending weekly rounds, where Henry is a regular attender.

This is not to say that all work and no play is his motto. He is, as we all know, an excellent raconteur and a witty conversationalist with a wide knowledge of the human condition.

We all hope that Henry has an enjoyable retirement. His devoted wife Erica may at least expect him home for supper at a reasonable time, although I doubt that she is counting on it.

John U. Crichton

Vancouver, British Columbia

\section{Symposium to Honour Henry Dunn}

A symposium to honour Dr. Henry Dunn on the occasion of his 75th birthday was held in Vancouver on April 2 and 3, 1992. It was attended by approximately 100 friends, colleagues, former students and others and emphasized the central and uniquely productive role that $\mathrm{Dr}$. Dunn has held in Canadian pediatric neurology during the last 40 years.

The first day was opened by guest speaker Dr. John Menkes talking on "From the Bedside to the Genome" as a personal account based on the steps leading to the discovery of kinky hair disease or Menkes Syndrome. Dr. Michael Brooke eloquently reviewed the "Current Status of Duchenne Dystrophy" and during the day the audience were treated to papers outlining the state of the art in "Parent of Origin Effects in Neurologic Disorders" by Dr. Judith Hall, Chairman of the Department of Pediatrics at the University of British Columbia, and on the "Molecular Genetics of Fragile-X Mental Retardation" by Dr. Sylvie Langlois. There were first rate reviews of SIDS by Dr. Margaret Norman, Subtypes of Autism by Dr. Linda Eaves based on the extensive experience of the SunnyHill Hospital team, the current state of Biochemical Disease in Vancouver in 1992 by Dr. Derek Applegarth and the B.C. experience of lead poisoning in children by Dr. Gillian Lockitch. It was remarkable how these speakers were able to relate the influence of Dr. Dunn in these very diverse areas including the fact that $\mathrm{Dr}$. Dunn was the first author in the original paper that described Xlinked mental retardation in an extensive pedigree which became eponomously named Renpennings Syndrome after the second author and which was later clearly the Fragile- $X$ syndrome. Further excellent papers included ones on Modelling the Epileptic Focus in Rolandic Epilepsy by Dr. Peter Wong, on the prediction of Which Children Develop Febrile Seizures by Dr. Carol Camfield of Halifax and on the current Vancouver research in the treatment of Cerebral Palsy exemplified by the Baclofen Trial under Dr. Robert Armstrong and the Selective Rhizotomy Programme under Dr. Paul Steinbok. Dr. Richard Appleton from the U.K. spoke on Intellectual Performance in patients with Duchenne Dystrophy and Dr. Lorne Clarke brought us up to date with "Advances in Mitochondrial Disease".

A dinner to honour Dr. Dunn was held that evening at which reminiscences of Henry were freely given and he was gently warmed if not lightly roasted. His brother, also a physician, 